\title{
Solvothermal synthesis of defect-rich mixed 1T-2H MoS nanoflowers for enhanced hydrodesulfurization
}

Hongwei Cao ${ }^{\text {a }}$, Zhe Bai ${ }^{\text {a }}$, Yueting Li ${ }^{\text {a }}$, Zhourong Xiao ${ }^{\text {a }}$, Xiangwen Zhang a,b,

\author{
Guozhu Li a,b *
}

${ }^{a}$ Key Laboratory for Green Chemical Technology of Ministry of Education, School of Chemical Engineering and Technology, Tianjin University, Tianjin 300072, China

b Collaborative Innovation Center of Chemical Science and Engineering (Tianjin), Tianjin 300072, China

*Corresponding author. Tel. /fax: +86 2227892340.

E-mail address: gzli@tju.edu.cn

The supporting information contains 4 pages, 1 figure, 1 scheme, and 1 table. 


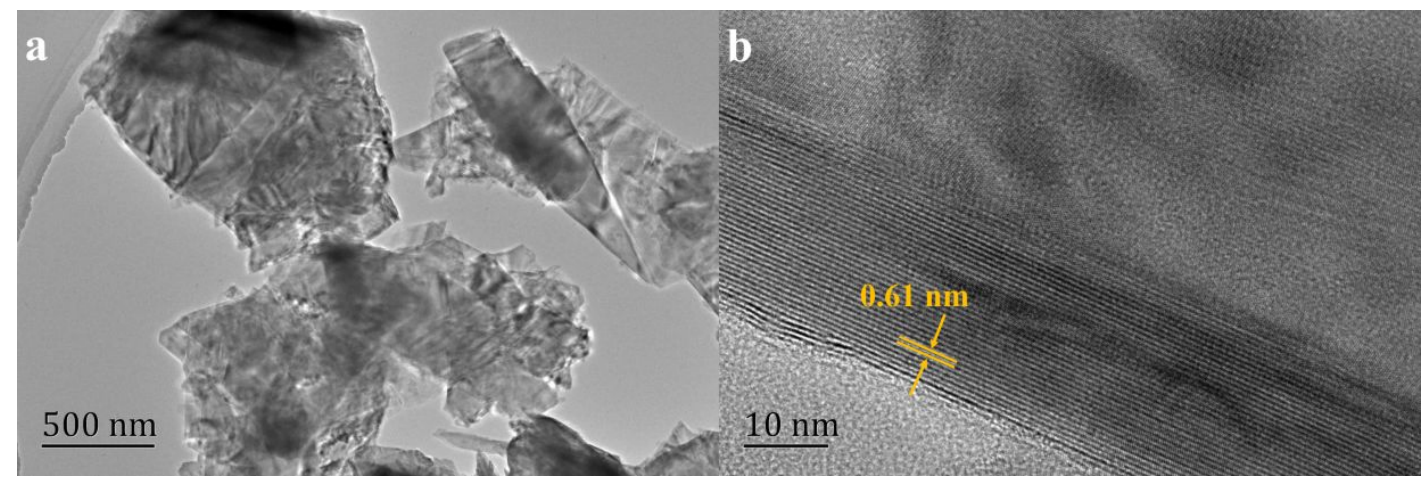

Figure S1. TEM image of the commercial $\mathrm{MoS}_{2}$. 


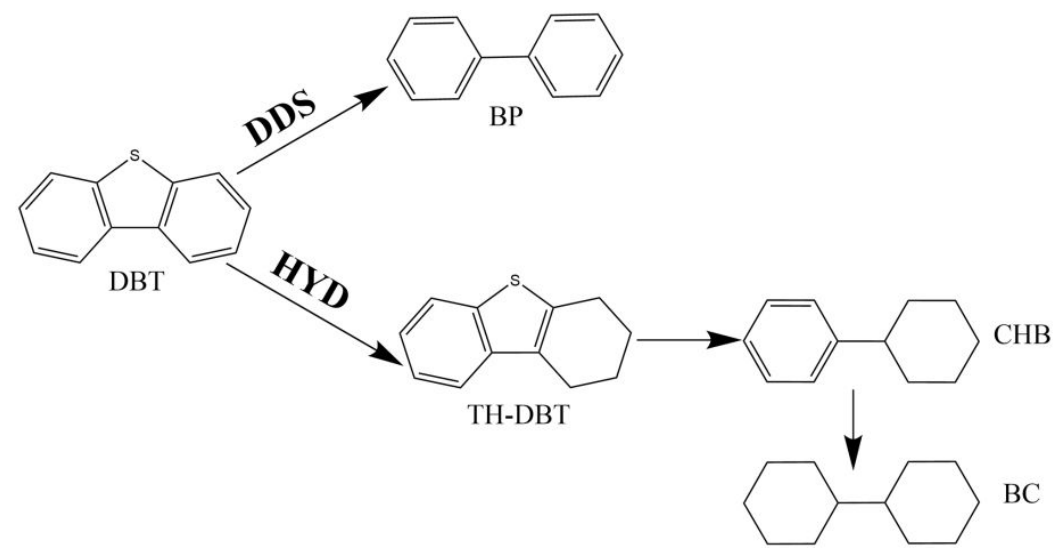

Scheme S1. Reaction pathway for hydrodesulfurization of DBT 
Table S1. The conversion, selectivity and ratio of HYD/DDS in the reaction products in hydrodesulfurization of DBT.

\begin{tabular}{|c|c|c|c|c|c|}
\hline \multirow{5}{*}{ Catalyst } & & & & & Rate \\
\hline & Conversion & HYD & DDS & HYD & \multirow{4}{*}{$\begin{array}{c}\left(10^{-9} \times \mathrm{mol}\right. \\
\left.\mathrm{g}^{-1} \mathrm{~s}^{-1}\right)\end{array}$} \\
\hline & \multirow{3}{*}{$(\%)$} & \multirow{3}{*}{$(\%)$} & \multirow{3}{*}{$(\%)$} & & \\
\hline & & & & /DDS & \\
\hline & & & & & \\
\hline $\mathrm{MoS}_{2}$-commerce & 8 & 63 & 37 & 1.7 & 14 \\
\hline $\mathrm{MoS}_{2}$-water & 32 & 64 & 36 & 1.8 & 58 \\
\hline $\mathrm{MoS}_{2}$-water-gly & 55 & 90 & 10 & 9.0 & 99 \\
\hline $\mathrm{MoS}_{2}$-water-ethanol & 61 & 88 & 12 & 7.3 & 110 \\
\hline $\mathrm{MoS}_{2}$-water-ethanol-gly & 80 & 89 & 11 & 8.0 & 144 \\
\hline \multicolumn{6}{|l|}{$\mathrm{MoS}_{2}$-water-ethanol-gly } \\
\hline & 84 & 88 & 12 & 7.3 & 151 \\
\hline recycle & & & & & \\
\hline
\end{tabular}

